\title{
A Study on Evacuation Safety at Inundated Stairs by using Real-scale Hydraulic Model Experiment
}

\author{
Myounghwan Kim ${ }^{1, *}$, Du Han Lee ${ }^{1}$, Ji-sung $\mathrm{Kim}^{1}$, Jung Hyun Eom ${ }^{2}$ \\ ${ }^{1}$ Korea Institute of Civil Engineering and Building Technology, Hydro Science and Engineering \\ Research Institute, 283 Goyang-daero Ilsanseo-gu Goyang-si Gyeonggi-do, South Korea \\ ${ }^{2}$ Graduate School of Inha University, 100 Inha-ro Nam-gu Incheon, South Korea
}

\begin{abstract}
In recent years, sudden and local downpours in Korea have become more frequent. These rainfall patterns increase load on drainage system and reduce ability to exclude inland water, leading to flooding. If such rainfall patterns lead to flash floods especially in dense urban areas, sudden submergence of underground spaces by floods can be a fatal threat to life. Therefore, it is very important to secure evacuation routes in case of inundated underground spaces. In this study, we tried to determine evacuation safety by understanding hydraulic characteristics of inundated stairs that could become evacuation routes in underground spaces. For this purpose, water depth and volume flow rate were measured at each point of inundated stairs, and data obtained from results were used to evaluate evacuation safety at each step.
\end{abstract}

\section{Introduction}

\subsection{Purpose and necessity}

Due to recent climate change, sudden and unexpected local downpours are occurring in South Korea. These rainfall patterns increase burden of existing channel or streams in urban areas. This results in decrease in drainage of inner basin capacity in urban areas, resulting in urban floods. Typical flood risk facilities in urban areas are underground facilities. These underground facilities may be subject to severe flood damage due to backwater of channel and flooding of stairs and vents. In South Korea, there are many underground facilities such as subway station, underground roads, underground shopping malls, and underground sidewalks. People in these facilities can only be safe if they can easily evacuate to ground as soon as flooding occurs. In flood, stairs may be only escape from these underground facilities. However, it is possible to flood into these stairs in urban areas. And if you do not cope properly at this time, there will be a lot of casualties. In this study, we fabricated an approximately 20 -step stairs model of same size as actual one. In order to show possible hydraulic range of evacuation and to suggest appropriate conditions in inundated stairs,

\footnotetext{
*Corresponding author: narrowgate@kict.re.kr
} 
velocity and water level during flood flow situation were measured at each step in entire stairs. Lastly results were used to examine possibility of evacuation of people at each point of stairs according to volume flow rate into stairs.

\subsection{Past works}

Evacuation safety of human life in inundated situations has been studied by several researchers. Many researchers used critical depth-velocity $\left(h v_{c}\right)$, which is product of water depth and velocity for quantitative assessment of flood safety. Abt et al.[6] used a human concrete column and 20 adults in the water channel to determine critical depth-velocity in a submerged condition. The empirical formula with addition of human height and body weight also were was used. In the RESCDAM study, Karvonen et al.[5] proposed the formula for adding human height and body weight to determination of thresholds that can be moved normally when immersed in seven subjects between 17 and 60 years of age. Ramsbottom et al.[1] and Penning-Rowsell et al.[2] applied water depth and velocity as well as debris transfer risk analysis in flood flows. They analysed flood risk by adding debris factor $(D F)$ to critical depth-velocity. There are also studies evaluating evacuation safety in inundated situations by methods other than critical water velocity. Ishigaki et al.[7, $8,9,10]$ and Onishi et al.[4] assessed openness of underwater door in order to ascertain conditions for safe evacuation in underground space. In their study, evacuation safety was analysed by using the specific force per unit width $\left(M_{0}\right)$. In Korea, Joo and Kim[3] described difference in evacuation time according to use of handrails in inundated stairs, and analysed evacuation safety according to type of shoes and whether to wear shoes. Except for the work of Ishigaki and Joo, study of evacuation safety in most of flood conditions assumes flooding in a flat location rather than stairs, and deals with flooding on ground space rather than underground space. Therefore, in this study, the method used in the study of Ishigaki et al.[9] were selected for judging whether to possibly evacuate from inundated stairs and properly evaluating evacuation safety.

\section{Methods}

\subsection{The criteria of evacuation safety}

Ishigaki et al.[9] analysed possibility of people walking in inundated corridors and stairs using a real-scale staircase model to evaluate safe evacuation criteria in underground flooding situations. In the experiment, he determined that velocity and water depth of water influenced people's walking in a inundated situation, and judged possibility of evacuation of people by the unit force per square meter $\left(M_{0}\right)$ in order to quantify it. Ishigaki's formula[9] for calculating the specific force per unit width is as follows.

$$
M_{O}\left(m^{3} / m\right)=u^{2} h / g+h^{2} / 2
$$

Here, $u$ is velocity, $h$ is water depth, and $g$ is the gravitational acceleration.

Ishigaki et al.[9] used the experimental results to show evacuation safety standards for underground space by age and sex in the following table and figure. Table. 1 shows Criteria of safe evacuation presented by the specific force per unit width, and Fig. 1 shows Criteria of safe evacuation presented by velocity and water depth. In this study, we calculated the specific force per unit width at each step, using velocity and water depth measured in the experiment, compared these values with criteria of evacuation safety proposed by Ishigaki et al.[9] And evacuation safety at each step of the stairs was evaluated. 
Table 1. Criteria of safe evacuation presented by the specific force per unit width, $M_{0}\left(\mathrm{~m}^{3} / \mathrm{m}\right)$.[9]

\begin{tabular}{|c|c|c|}
\hline & Limit of safe evacuation & Difficult without any help \\
\hline Male & 0.125 & 0.250 \\
\hline Elderly male & 0.100 & 0.200 \\
\hline Female & 0.100 & 0.200 \\
\hline Elderly female & 0.080 & 0.160 \\
\hline
\end{tabular}

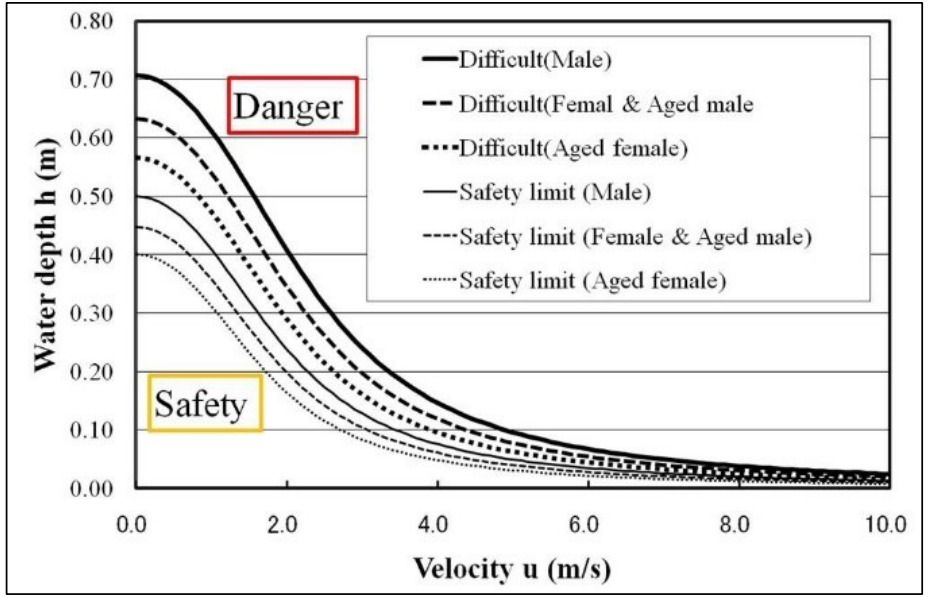

Fig. 1. Criteria of safe evacuation described by water depth and velocity.[9]

\subsection{Stairs model production}

In this study, we made stairs model of real scale as actual with reference to building regulations of Korea's "Regulations on Housing Construction Standards". This staircase model has 20 steps and its width is $1 \mathrm{~m}$. And its tread was designed at $0.295 \mathrm{~m}$, considering foot size of an adult male. Remaining details are same as Table. 2, and overall structure of experimental stairs model is same as Fig. 2.

Table 2. Specification of experimental stairs model.

\begin{tabular}{|c|c|c|c|c|c|c|}
\hline Width(m) & Length(m) & Height(m) & $\begin{array}{c}\text { Number } \\
\text { of Step }\end{array}$ & $\operatorname{Tread(m)}$ & $\operatorname{Riser(m)}$ & $\operatorname{Slop}\left({ }^{\circ}\right)$ \\
\hline 1.0 & 5.9 & 2.9 & 20 & 0.295 & 0.145 & 26.6 \\
\hline
\end{tabular}




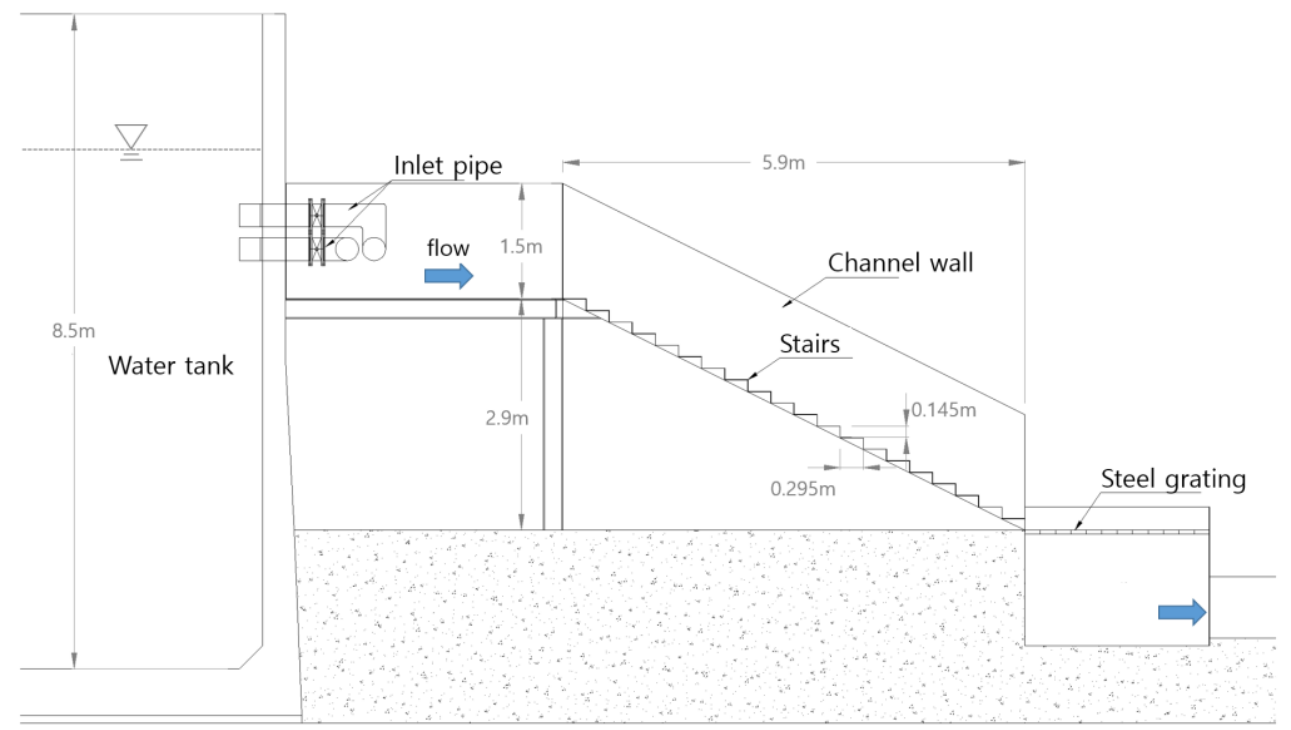

Fig. 2. Structure of real-scale experimental stairs model(River Experiment Center in Andong)

\subsection{Real-scale experiment to assess evacuation safety in inundated stairs}

Fig. 3 shows foreground, current meter and measuring points of a real scale stairs experiment. The experiment was carried out in all seven volume flow rate conditions. In this experiment, water depth was measured using scale marked on wall of stairs channel, and velocity was measured along the centre line of the stair channel using magnetic current meter that can be measured in field. Water depth and velocity were measured at same time, and velocity and water depth were measured up to 16th steps from downstream among the total of 20 steps.

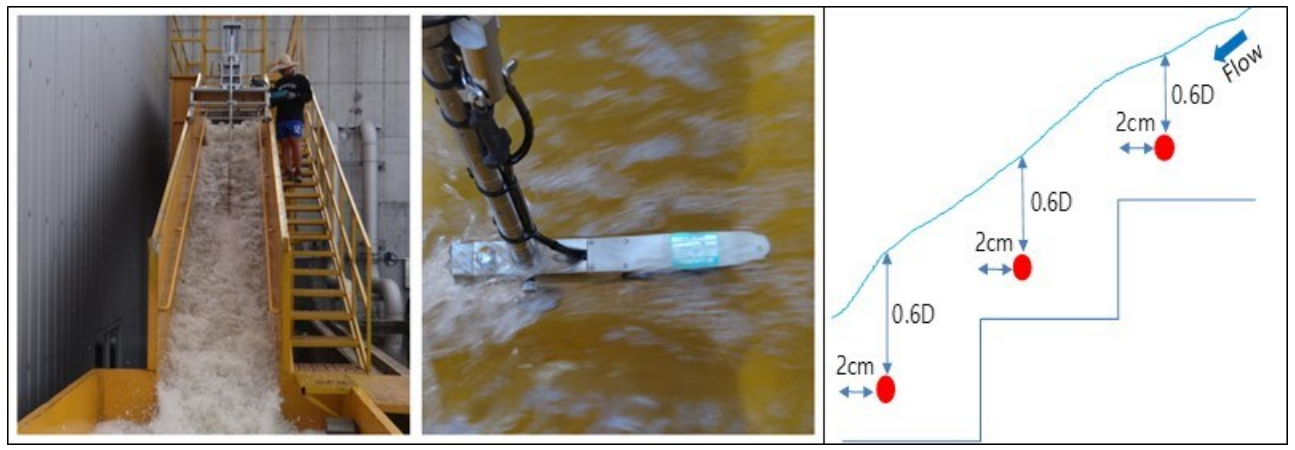

Fig. 3. Real-scale experiment and measuring point

Velocity and water depth were measured only up to 16th step because Ishigaki et al. (Fig. 4) [10] showed that the specific force per unit width from 16th step was almost similar to that from the corridor. Therefore, velocity and water depth above 16th step were not be widely used for evacuation safety evaluation of inundated stairs. 


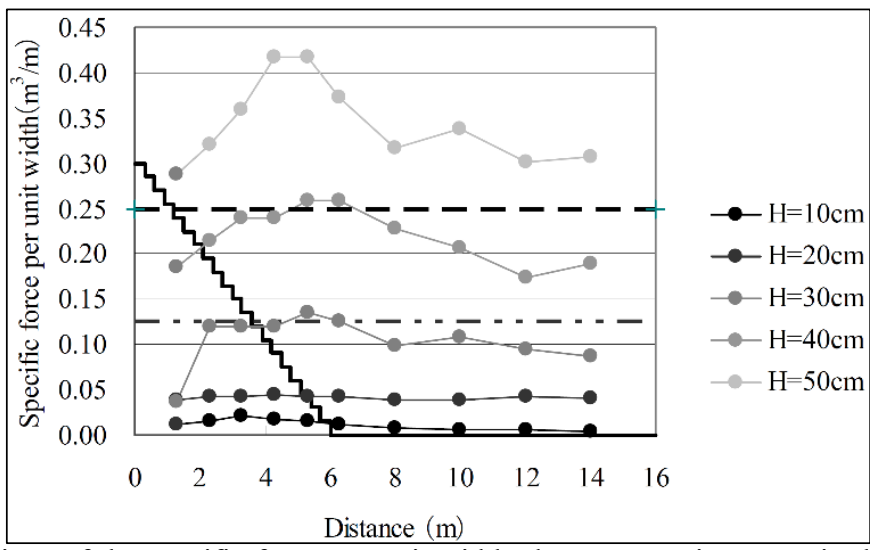

Fig. 4. Distributions of the specific force per unit width along evacuation route in the normal cases. Double dashed lines are the criterion of $\mathrm{u}^{2} \mathrm{~h} / \mathrm{g}+\mathrm{h}^{2} /=0.125$ for safe evacuation and the dashed lines are the limit of 0.250 for evacuation without any help.[10]

\section{Results and Discussion}

\subsection{Results}

The measured velocity and water depth at each stage were used to estimate the specific force per unit width. Fig. 5 shows difference among the specific force per unit width, velocity and water depth at each step of inundated stairs when volume flow rate is $0.81 \mathrm{~m}^{3} / \mathrm{s}$ in the experiment cases.

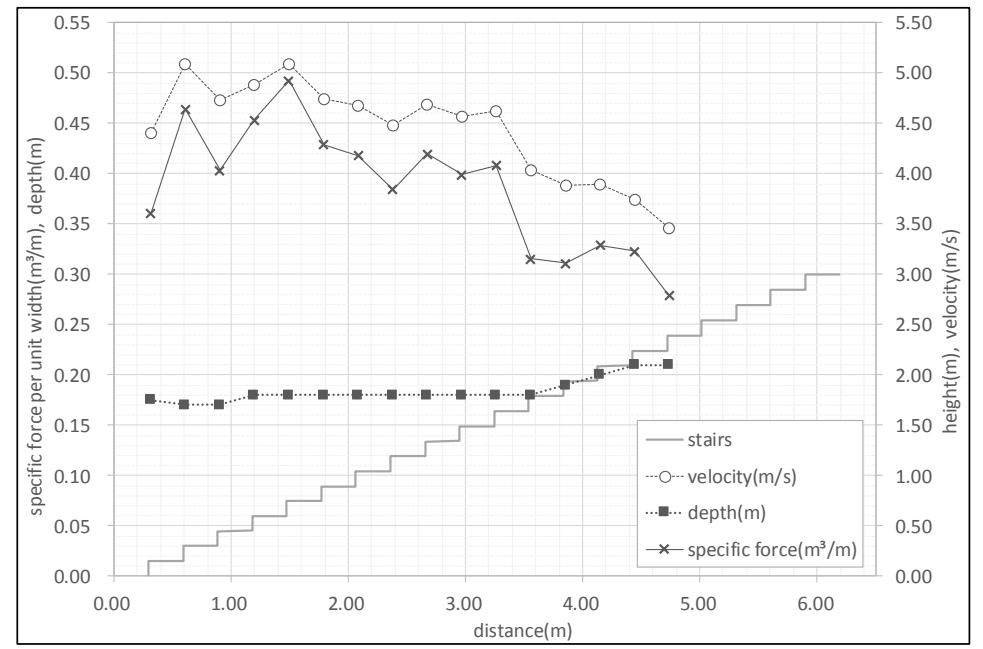

Fig. 5. Distribution of velocity, water depth, the specific force per unit width in inundated stairs. $\left(\mathrm{Q}=0.81 \mathrm{~m}^{3} / \mathrm{s}\right)$

Fig. 6 and 7 below are graphs showing evacuation safety according to the specific force per unit width at each step of the stairs using criteria of Table. 1[9] that was used in order to determine whether evacuation safety in Ishigaki's experiments.

Fig. 6 is the graph comparing the criteria line of the limit of safe evacuation according to Table. 1[9] and the specific force per unit width in this experiment. The measurement results show that in this case, adult males can safely evacuate up to the volume flow rate of 
$0.28 \mathrm{~m}^{3} / \mathrm{s}$ at all steps. And elderly males and adult females can safely evacuate above 5 th step when the volume flow rate is $0.28 \mathrm{~m}^{3} / \mathrm{s}$. finally, elderly females, the volume flow rate should be $0.13 \mathrm{~m}^{3} / \mathrm{s}$ for evacuation safety.

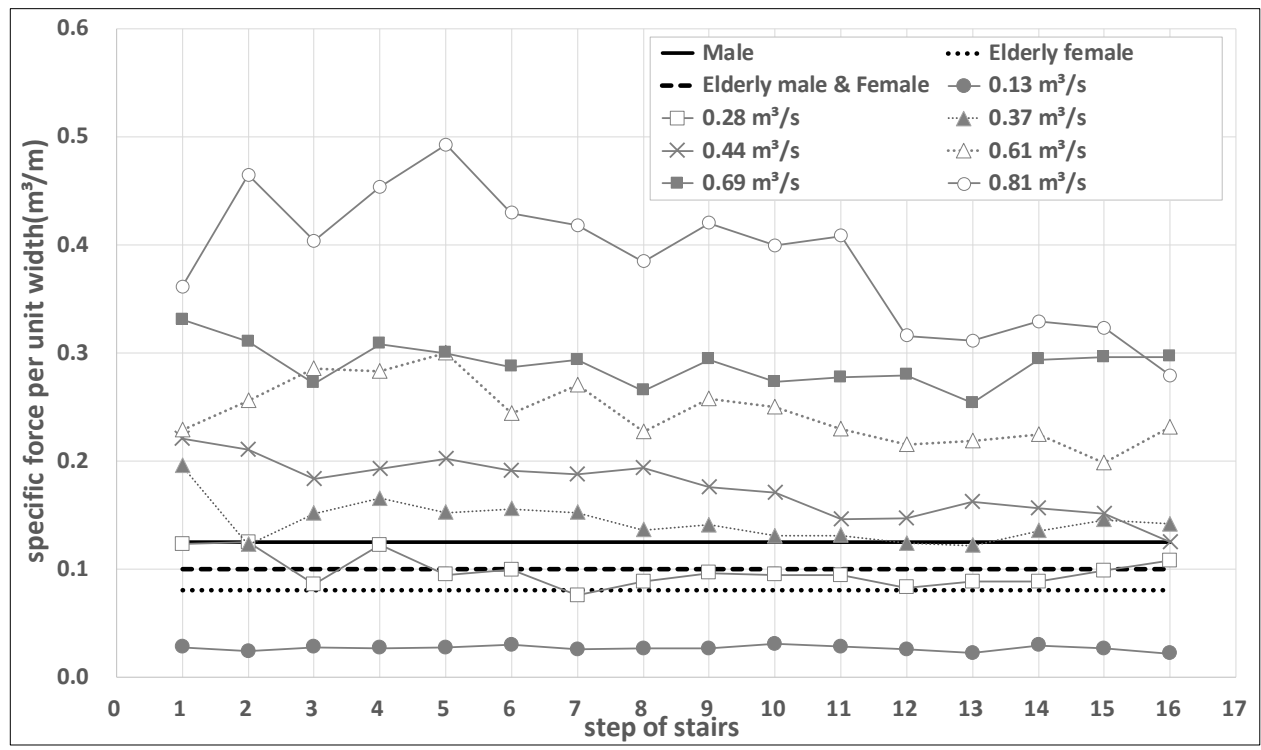

Fig. 6. Distribution of the specific force per unit width and limit of safe evacuation

Fig. 7 is the graph comparing the criteria line of difficult without any help according to Table. 1[9] and the specific force per unit width in this experiment. This criteria line represents the limit to which people can evacuate alone. In this case, adult males were evacuated above 10th step with volume flow rate of $0.61 \mathrm{~m}^{3} / \mathrm{s}$. And adult females and elderly males were evacuated above 5 th step of $0.44 \mathrm{~m}^{3} / \mathrm{s}$ volume flow rate, finally elderly females were relatively able to evacuate above 11 th step of $0.44 \mathrm{~m}^{3} / \mathrm{s}$ volume flow rate.

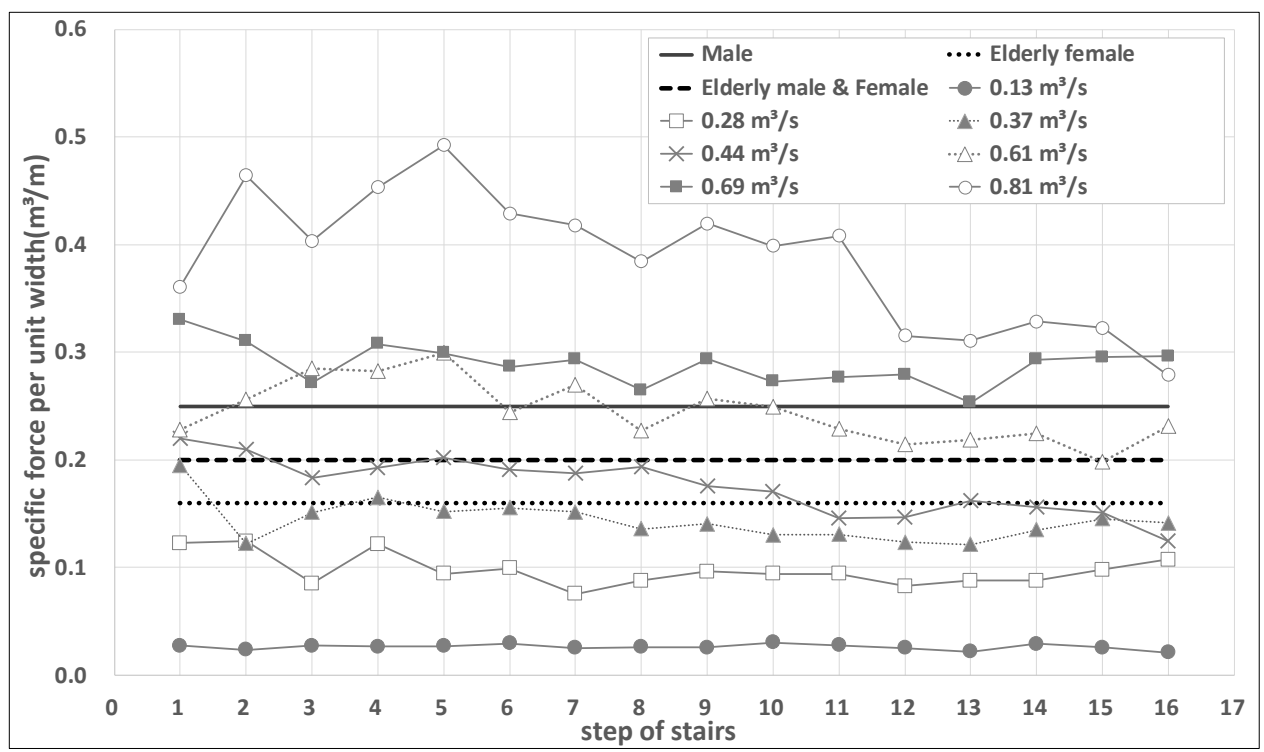

Fig. 7. Distribution of the specific force per unit width and difficult without any help 
Fig. 8 shows water depth results of these experiments which overlapped Fig. 1. The specific force per unit width or velocity can be used as standard to judge whether or not evacuation is safe in this study. However, these values are not suitable for ordinary people use to intuitively determine evacuation safety of inundated stairs in flooded underground areas. Therefore, in this study we applied water depth results to Fig. 1. As a result, as shown in Fig. 8, only water depth can be used to determine evacuation safety of inundated stairs. This graph shows that it is difficult for evacuation of all persons at water depths of $0.20 \mathrm{~m}$ or more, and that it is difficult for evacuation of adult women and elderly men at water depths of $0.15 \mathrm{~m}$ or more. It also shows that it is passable for elderly women to evacuate when water depth is less than $0.10 \mathrm{~m}$.

One of factors that have greatest influence on evacuation from underground flooding is a psychological state of people. People may be embarrassed in the flood situation that they have not experienced in everyday life, and even in inundated stairs where they can fully evacuate, they may not even try to evacuate through staircase due to a lack of information related to evacuation. At this time, if information on evacuation safety according to water depth of flooding can be found in guide signs, etc., people will be able to evacuate act calmly in a stable state of psychology.

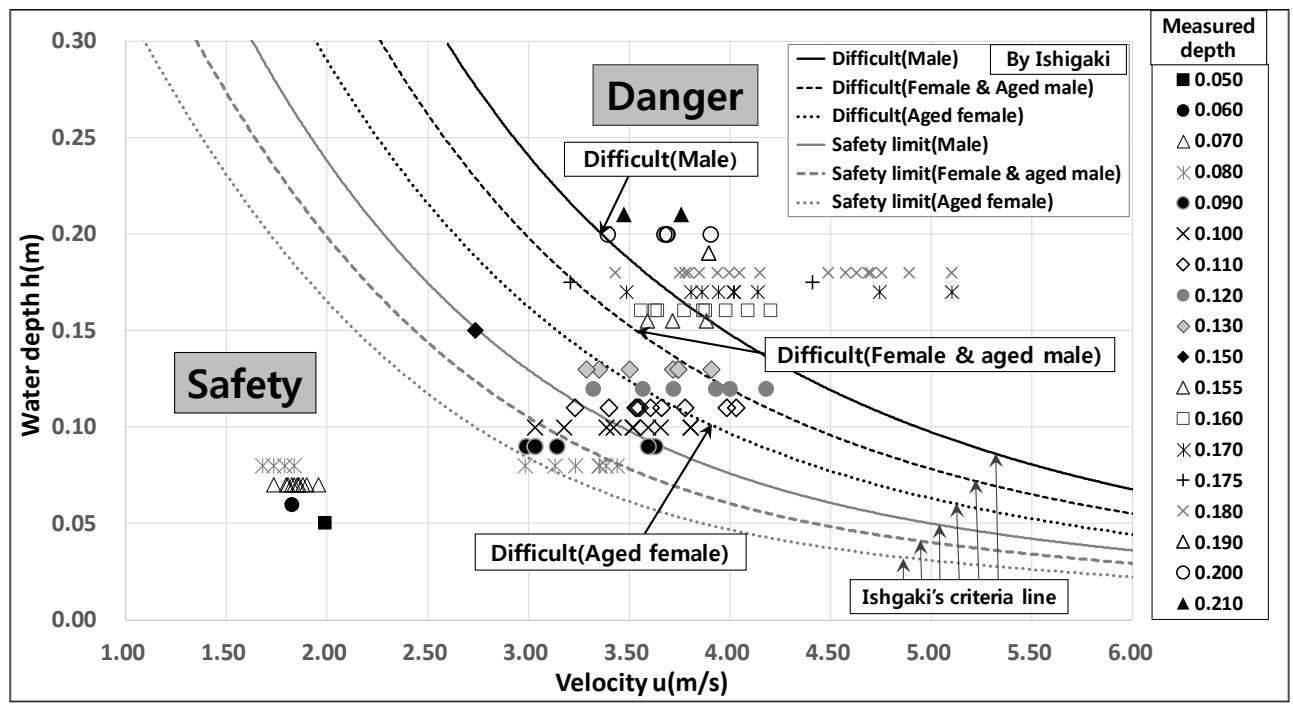

Fig. 8. Determination of safe evacuation criteria using water depth overlapped Fig. 1 by Ishigaki. This graph was made by digitizing part of Fig. 1.[9]

\subsection{Closing discussion}

In the study, evacuation safety at inundated stairs was discussed. The main conclusions are as follows.

1) Evacuation safety of inundated stairs varies with each step of the stairs. In all experimental conditions, high steps is safe to evacuate than low steps in inundated stairs. According to this result, whether to pass from low steps in inundation stairs can determine success or failure of evacuation at inundated stairs.

2) Evacuation safety at inundated stairs can be evaluated not only the specific force per unit width but also by simple water depth. These results can be used to evacuate public ordinary people from flooded underground space through safe and easy inundated stairs. According to the results of this study, it may contribute greatly to evacuate people in flooded underground space just by a simple scale display to check water depth on stairs wall. 
We suggested evacuation safety of each step in inundated stairs using specific force per unit width. In addition, we evaluated evacuation safety of inundated stairs using water depth so that public can more easily understand information on evacuation safety in underground flooding situations. But, this experiment results alone are not sufficient to evaluate evacuation safety of all inundated stairs, because this experiment was carried out in an only one type of stairs. Therefore, further experimentation is needed on more types of stairs. In addition, the points indicated by the arrows in Fig. 8 show that there is a limit of velocity according to each water depth in inundated stairs. As a result, the specific force per unit width is expected to have a limit according to each water depth in inundated stairs. Peculiarly enough, some velocity limit point according to water depth meet Ishigaki's[9] criteria lines of evacuation safety. These results are thought to come from the characteristic of stair flows. Therefore, we also need to study normal depth and skimming flow that occur in future stair flows. If above mentioned studies are further progressed, it will help to evacuate people in flooded underground facilities.

\section{Acknowledgements}

This subject was supported by "Field Evaluation of Best Available Technique for Algae Control in River" (code 18AWMP-B098633-04) funded by MOLIT(Ministry of Land, Infrastructure and Transport).

\section{References}

1. D. Ramsbottom, S. Wade, V. Bain, M. Hassan, E. Penning-Rowsell, T. Wilson, A. Fernandez, M. House and P. Floyd, Flood Risks to People. Phase 2. FD2321/ IR2.Department for the Environment (Food \& Rural Aff./Env. Age., 2004)

2. E.C. Penning-Rowsell, P. Floyd, D. Ramsbottom, and S. Surendran, Nat. Hazards, 36, 1-2 (2005)

3. J. Joo, T. H. Kim, J. Korean Soc. Hazard Mitig., 15, 2 (2015)

4. Onishi Y., Ishigaki, T., Baba, Y. and Toda, K. J. Hydraul. Eng., 27, 1 (2009)

5. R.A. Karvonen, A. Hepojoki, H.K. Huhta and A. Louhio, RESCDAM Final Report, (TKK, 2000)

6. S.R. Abt, R.J. Wittler, A. Taylor, and D.J. Love, Wat. Res. Bull., 25, 4 (1989)

7. T. Ishigaki, R. Kawanaka, Y. Onishi, H. Shimada, K. Toda and Y. Baba, Proc. of 16th APD-IAHR (2008b)

8. T. Ishigaki, Y. Asai, Y. Nakahata, H. Shimada, Y. Baba and K. Toda, Wat. Sci. \& Tech., 62, 8 (2010).

9. T. Ishigaki, T. Ozaki, T. Inoue, H. Shimada and K. Toda, 12th ICUD (2011)

10. T. Ishigaki, Y. Onishi, Y. Asai, K. Toda and H. Shimada, 11th ICUD (2008a) 